\title{
Lipase-Catalyzed Synthesis of S-Naproxenal oleins
}

\author{
Jia-ying $\operatorname{Xin}^{1,2, a^{*}}$, Jia-wen Jiang ${ }^{1, b}$ \\ ${ }^{1}$ Key Laboratory for Food Science \& Engineering, Harbin University of Commerce, Harbin 150076, \\ People's Republic of China \\ ${ }^{2}$ State Key Laboratory for Oxo Synthesis \& Selective Oxidation, Lanzhou Institute of Chemical \\ Physics, Chinese Academy of Sciences, Lanzhou 730000, People's Republic of China \\ axinjiayingvip@163.com.cn, ${ }^{b}$ t13946155392@126.com
}

Keywords: Naproxen; Naproxenal oleins; Prodrugs; Trolein; Transesterification.

\begin{abstract}
S-Naproxenal oleins are compounds of S-Naproxen ((S)-2-(6-methoxy-2-naphthyl) propionic acid) and olein connected by an ester bond and can be used as potential prodrug in anti-inflammatory. In the present work, we describe for the first time the lipase-catalyzed synthesis of the S-Naproxenal oleins by transesterification between S-Naproxen and triolein in organic solvents medium. The ability of lipases to catalyze the transesterification between S-Naproxen and triolein was investigated. Only the lipase from Candida rugosa and the immobilized lipase B from Candida antarctica (Novozym 435) catalyzed the transesterification. The influences of reaction condition on the combined yield of S-Naproxenal diolein (NDO) and S-Naproxenal monoolein (NMO) were investigated. Water activity $\left(\mathrm{a}_{\mathrm{w}}\right)$ had an obvious influence on transesterification efficacy. A maximal combined yield of $23.1 \%$ of S-Naproxenal diolein (NDO) and S-Naproxenal monoolein (NMO) was obtained under optimum condition. These results indicated the industrial potential of the operation scheme developed in this study.
\end{abstract}

\section{Introduction}

(S)-2-(6-methoxy-2-naphthyl) propionic acid (S-Naproxen) is an important member of the family of 2-aryl propionic acid derivatives which are widely used as non-steroidal anti-inflammatory drug (NSAIDs) ${ }^{[1]}$. Free carboxylic group of S-Naproxen has severe gastrointestinal side effects on oral administration that restricts its use ${ }^{[2]}$. S-Naproxen can cause undesirable gastrointestinal toxic effects such as bleeding, dyspepsia and peptic ulcers. To overcome this, acidic group of S-Naproxen can be temporarily masked by synthesizing glyceride ester prodrugs, which can pass through the stomach without releasing active drug in significant quantity and also increase the absorption pertaining to the natural triglycerides ${ }^{[3]}$.

Earlier, the glyceride prodrugs of some NSAIDs like ibuprofen ${ }^{[4]}$, biphenyl acetic acid ${ }^{[5]}$, mefenamic acid ${ }^{[6]}$, asprin ${ }^{[7]}$ could be synthesized by chemical methods using inorganic acid as catalysts at high temperature. The unstable NSAIDs resulted in the formation of by-products easily. As an alternative, to avoid any possible harmful effects from chemically synthesized product, the use of lipases to catalyze the synthesis of glyceride ester prodrugs of S-Naproxen may be a much more promising method.

S-Naproxenal oleins are compounds of S-Naproxen and olein connected by an ester bond and can be used as potential prodrugs in anti-inflammatory ${ }^{[8]}$. In the present work, we describe for the first time the lipase-catalyzed synthesis of the S-Naproxenal oleins by transesterification between S-Naproxen and triolein in organic solvents medium (Figure1). 


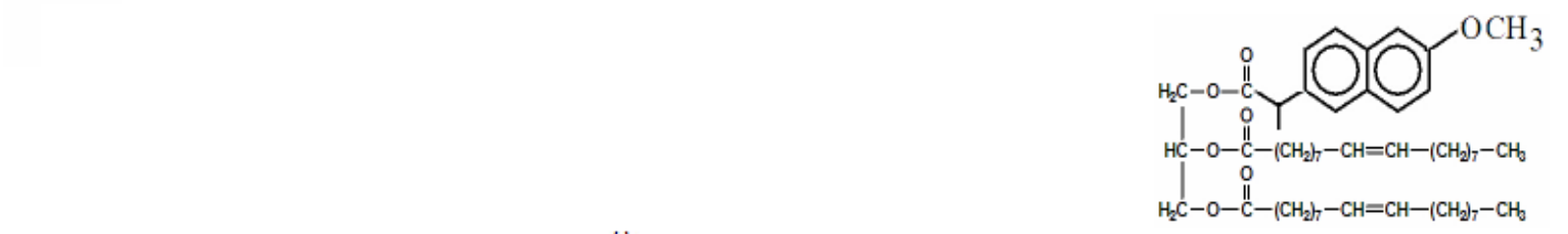

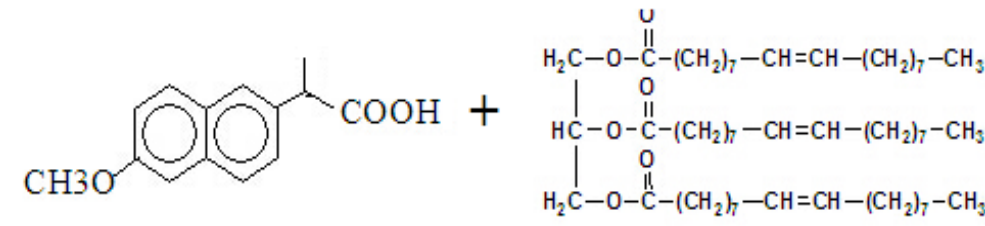

S-Naproxen

triolein

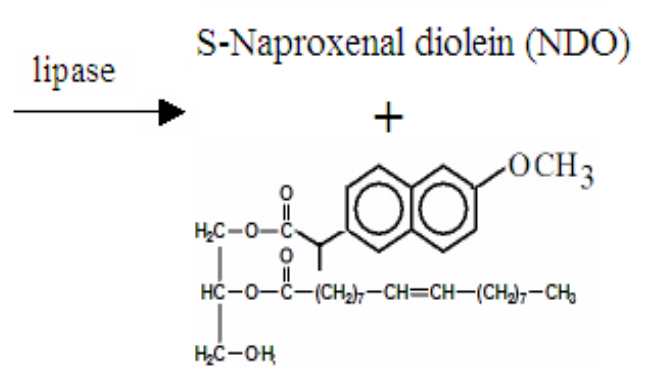

S-Naproxenal monoolein (NMO)

Figure. 1 Lipase-catalyzed transesterification of Naproxen and triolein

Naproxenal group substitution at the glycerol sn-1 position is shown for simplicity as the regioselectivity of the reaction is unknown.

\section{Materials and methods}

Lipase. Lipase from Aspergillus niger (Lipase AS "Amano" powder, $\geqslant 12,000 \mathrm{U} / \mathrm{g}$ ), Lipase from Pseudomonas fluorescens (Lipase AK “Amano" powder, $\geqslant 20,000 \mathrm{U} / \mathrm{g}$ ), Lipase from Burkholderia cepacia (Lipase PS “Amano" IM, immobilized on diatomite, $500 \mathrm{U} / \mathrm{g}$ solid enzyme) were purchased from Amano International Enzyme Co. (Nagoya, Japan).Novozym 435 (Candida antarctica lipase immobilized on polyacrylic resin, with an activity of $\geqslant 10,000 \mathrm{U} / \mathrm{g}$ solid enzyme), was purchased from Novozymes A/S (Bagsvaerd, Denmark). Porcine pancreas lipase Type II (powder, $\geqslant 30 \mathrm{U} / \mathrm{mg}$ ) and Candida rugosa lipase Type VII (powder, $\geqslant 700 \mathrm{U} / \mathrm{mg}$ ) were purchased from Sigma.

Water activity pre-equilibration of reaction medium. Pre-equilibration was done at $25^{\circ} \mathrm{C}$. The solid adsorbent was $3 \AA$ molecular sieves $\left(\mathrm{a}_{\mathrm{w}}:<0.01\right)$. The saturated salt solutions used were prepared with $\operatorname{LiBr}\left(\mathrm{a}_{\mathrm{w}}: 0.07\right), \mathrm{LiCl}\left(\mathrm{a}_{\mathrm{w}}: 0.11\right), \mathrm{CH}_{3} \mathrm{COOK}\left(\mathrm{a}_{\mathrm{w}}: 0.23\right),(\mathrm{MgNO} 3) \cdot 6 \mathrm{H}_{2} \mathrm{O}\left(\mathrm{a}_{\mathrm{w}}: 0.54\right), \mathrm{NaCl}\left(\mathrm{a}_{\mathrm{w}}\right.$ : $0.75), \mathrm{KCl}\left(\mathrm{a}_{\mathrm{w}}: 0.85\right), \mathrm{K}_{2} \mathrm{Cr}_{2} \mathrm{O}_{7}\left(\mathrm{a}_{\mathrm{w}}: 0.98\right){ }^{[9]}$. By equilibrating lipase and substrates (i.e. S-Naproxen and triolein) with saturated salt solutions or $3 \mathrm{~A}$ molecular sieves, the initial $\mathrm{a}_{\mathrm{w}}$ for the reaction can be fixed over a broad range from $<0.01$ to 0.98 .

Procedure for lipase catalyzed transesterification. Transesterification reactions were conducted in 100-mL closed, screw-capped glass vials. S-Naproxen and triolein were dissolved together in organic solvent medium. Before the start of the reaction, the substrates (i.e. S-Naproxen and triolein), organic solvent and the lipase were pre-equilibrated for at least $120 \mathrm{~h}$ in separate sealed containers enclosed with saturated salt solutions or solid adsorbent to establish fixed $\mathrm{a}_{\mathrm{w}}$ for transesterification.

Reactions were performed through the addition of lipase to the organic solvent medium containing S-Naproxen and triolein in a 100-mL flask. When the lipase was added, glass vials were placed up right on a magnetic stirrer $(200 \mathrm{rpm})$ and incubated at $30-32^{\circ} \mathrm{C}$.

Monitoring and analysis of reaction mixtures. Analysis of the mixture composition was performed regularly. Samples were diluted 1:10 (vol/vol) in acetone and analyzed by thin-layer chromatography (TLC). The TLC migration was carried out with a solvent mixture of ethyl ether/hexane/ice acetic acid (15:85:1, v/v/v). The TLC plates were visualized under UV. Results were estimated from intensity of spots on TLC. The yields were calculated based on the total peak area of Naproxenal diolein (NDO), Naproxenal monoolein (NMO), and Naproxen. The sum of all Naproxenal species peak areas remained constant over the time course of the reaction, allowing accurate NDO and 
NMO yields to be calculated as the percentage ratio of the NDO and NMO peak area to the total peak area of all Naproxenal species.

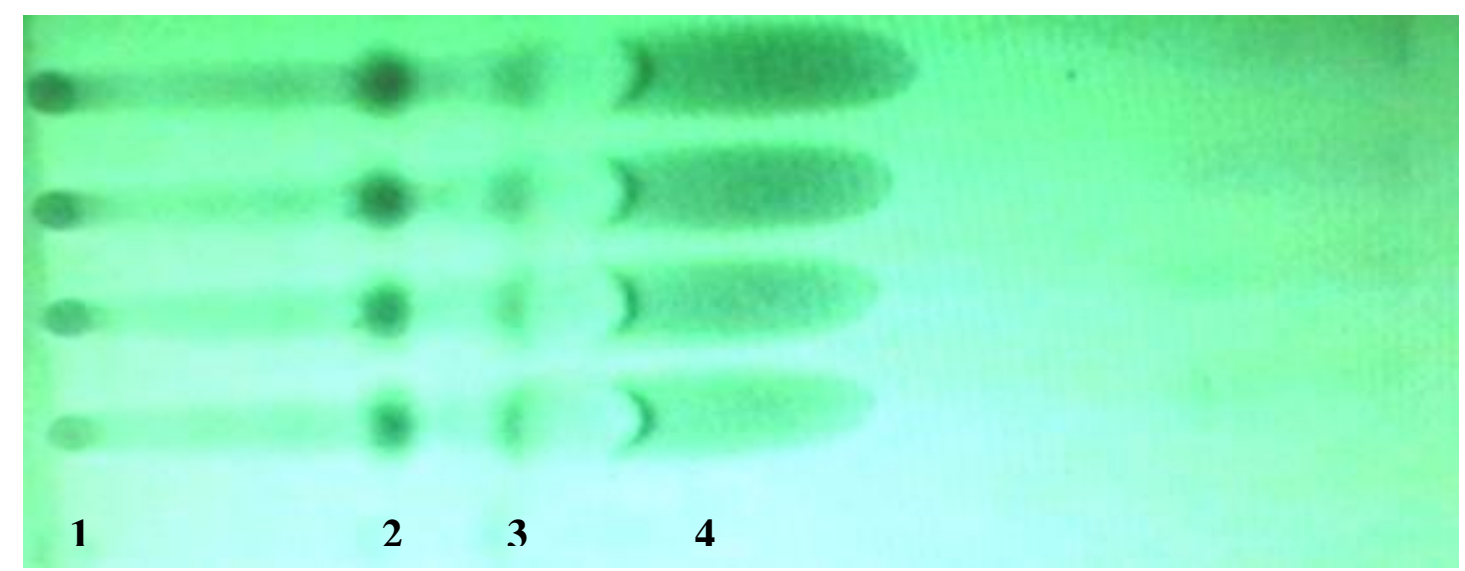

Figure. 2 Thin-layer chromatography (TLC) of lipase-catalyzed transesterification between S-Naproxen and triolein

1. origin; 2. Naproxen; 3 Naproxenal monoolein (NMO); 4. Naproxenal diolein (NDO)

\section{Results and discussion}

Six lipases from different sources (Candida rugosa lipase, Lipase AS, Lipase AK, Lipase PS. Novozym 435 lipase and Porcine pancreas lipase) were screened and evaluated for their ability to catalyze the transesterification reaction. Only Candida rugosa lipase and Novozym 435 lipase catalyzed the transesterification. However, Novozym 435 lipase gave rise to slower transesterification rate than Candida rugosa lipase. Therefore, Candida rugosa lipase was selected as the biocatalyst in the following experiments.

By using Candida rugosa lipase as catalyst, an enzymatic synthesis of S-Naproxenal oleins from S-Naproxen with triolein was successfully carried out. It has been observed that water activity $\left(\mathrm{a}_{\mathrm{w}}\right)$ had obvious influence on transesterification efficacy. The combined yield of Naproxenal diolein (NDO) and Naproxenal monoolein (NMO) decreased with increasing aw from $<0.01$ to 0.98 .

The influences of reaction medium on the yield of Naproxenal oleins was also studied. Isooctane has been found to be the optimal organic solvent of all the solvents that had been studied. The yield $16.5 \%$ achieved in isooctane $\left(\log \mathrm{P}=4.5^{[10]}\right)$, which was higher than the corresponding reactions yield that used n-hexane $\left(\log P=3.5^{[10]}\right)$ or toluene $\left(\log P=2.5^{[10]}\right)$.

The molar ratio of one substrate to another is an important parameter affecting the reaction equilibrium. The effect of molar ratio of S-Naproxen to triolein on the lipase-catalyzed transesterification was investigated. The Naproxen concentration was fixed at $1.0 \mathrm{mmol}$ while the triolein concentration varied from 0.5 to $4.0 \mathrm{mmol}$. When the triolein/Naproxen molar ratio increased, the combined yield of Naproxenal diolein (NDO) and Naproxenal monoolein (NMO) increased and reached a maximum at a ratio of 3/1. The influence of the molar ratio of the substrates on the yield may be explained by a thermodynamical shift of the equilibrium in favour of the synthesis of the ester due to triolein excess. However, for a further increase in triolein content, the synthesis yield was declined slightly.

Finally, a maximal combined yield of $23.1 \%$ of S-Naproxenal diolein (NDO) and S-Naproxenal monoolein (NMO) was obtained using a 3/1 mole ratio of trioleins to S-Naproxen in isooctane under $30-32^{\circ} \mathrm{C}$ at $96 \mathrm{~h}$. 


\section{Acknowledgements}

The authors thank the Scientific Research Fund of Heilongjiang Province (GC 13C111) for support.

\section{References}

[1] C. S. Chang, C. C. Su, J. R. Zhuang, S. W Tsai, Enhancement of enantioselectivity on the synthesis of (S)-naproxen morpholinoalkyl ester prodrugs in organic solvents using isopropanol-dried immobilized lipase, Journal of Molecular Catalysis B: Enzymatic 30 (2004) 151-157

[2] P. Sharma, S. Yadav, R. Pahwa, D. Kaushik and S. Jain, Synthesis and Evaluation of Novel Prodrugs of Naproxen, Medicinal Chemistry Research, 20(2011) 648-655

[3] N. Bodor, Retrometabolic Approaches for Drug Design and Targeting, Pharmazie, 52(1997) $491-494$

[4] M. S. Y. Khan and M. Akhter, Synthesis, Pharmacol- ogical Activity and Hydrolytic Behavior of Glyceride Prodrugs of Ibuprofen, European Journal of Medicinal Chemistry, 40(2005) 371-376

[5] M. S. Y. Khan, M. Akhter and A. Husain, Synthesis Biological Evaluation and Kinetic Studies of Glyceride Prodrugs of Biphenyl Acetic Acid, Indian Journal of Chemistry, 45B(2006) 1014-1019

[6] M. S. Y. Khan and M. Akhter, Glyceride Derivatives as Potential Prodrugs: Synthesis, Biological Activity and Kinetic Studies of Glyceride Derivatives of Mefenamic Acid, Pharmazie, (2005) 60, 110-114.

[7] G. Y. Paris, D. L. Garmaise, D. G. Cimon, L. Swett, G. W. Carter and P. Young, Glycerides as Prodrugs: Syn-thesis and Antiinflammatory Activity of 1,3-Bis(alka- noyl)-2-(O-acetylsalicyloy) Glycerides (Aspirin Triglyc- erides), Journal of Medicinal Chemistry, (1979) 22, 683-687

[8] V. K. Redasani1, S. B. Bari, Synthesis and Evaluation of Glyceride Prodrugs of Naproxen, Open Journal of Medicinal Chemistry, (2013) 3, 87-92

[9] E. Wehtje, D. Costes, P. Adlercreutz, Enantioselectivity of lipases: effects of water activity. J. Mol. Catal. B-Enzym. (1997)3, 221-230.

[10] J. Y. Xin, S.B. Li, Y. Xu, L. L. Wang, Enzymatic resolution of (S)-(+)-Naproxen in a trapped aqueous-organic solvent biphase continuous reactor, Biotechnology and Bioengineering, (2000) 68, 78-83, 